\title{
Evaluation of metformin versus insulin in the management of gestational diabetes mellitus: a prospective comparative study
}

\author{
Shabana Munshi ${ }^{1}$, Shamim Khandaker ${ }^{2} *$ \\ ${ }^{1}$ Department of Obstetrics \& Gynecology, NRS Medical College, Entally, Kolkata-700014, West Bengal, India \\ ${ }^{2}$ Department of Obstetrics \& Gynecology, North Bengal Medical College, Sushrutanagar, Darjeeling-734012, West \\ Bengal, India
}

Received: 21 March 2014

Accepted: 2 April 2014

*Correspondence:

Dr. Shamim Khandaker,

E-mail: shamim_khandaker@yahoo.co.in

(C) 2014 Munshi S et al. This is an open-access article distributed under the terms of the Creative Commons Attribution Non-Commercial License, which permits unrestricted non-commercial use, distribution, and reproduction in any medium, provided the original work is properly cited.

\begin{abstract}
Background: Objectives of current study were to assess the efficacy of metformin in the management of Gestational Diabetes Mellitus (GDM) and to compare maternal fetal outcome between metformin and insulin in GDM.

Methods: It is a prospective comparative study performed in a tertiary centre. 100 women diagnosed with gestational diabetes mellitus according to Diabetes in Pregnancy Study group of India (DIPSI) criteria at booking and/or between 24-28 weeks of gestation.These women were divided randomly into two groups, 50 patients in each group and they are subjected to pharmacological treatment with either insulin or metformin. Optimum glycemic control between the two groups is studied along with maternal and fetal outcome.

Results: Our study to showed no significant difference in GDM with the use of metformin or insulin ( $\mathrm{P}=0.15) .84 \%$ of insulin group had good glycemic control whereas in metformin group, $72 \%$, achieved euglycemic state. Maternal and fetal outcome are also comparable between the two groups.

Conclusions: In GDM, glycaemic control can be done a combination of MNT (medical nutrition therapy), exercise and using the oral drug metformin without risk of teratogenicity or maternal hypoglycemia and with comparable neonatal outcome.
\end{abstract}

Keywords: Gestational diabetes mellitus, Metformin, Insulin

\section{INTRODUCTION}

Pregnancy is a potentially glucose intolerant condition. Insulin sensitivity decreases as the pregnancy advances. Of these women, some will develop Gestational Diabetes Mellitus (GDM) due to inadequate insulin secretion, particularly in obese women with pre-existing insulin resistance.

GDM is diagnosed in approximately $3-7 \%$ of pregnancies. ${ }^{2,3}$ The incidence of GDM increases in older and more obese pregnant women. GDM increases the risk of certain pregnancy complications like pregnancy induced hypertension and adverse perinatal outcome, it carries the risk of later development of type 2 diabetes mellitus (DM) $(75 \%))^{1,3,4}$

Prospective randomized controlled trials have recently demonstrated that effective treatment of hyperglycemia in women with GDM can reduce adverse perinatal outcomes. ${ }^{5}$ The main purpose of treatment is to prevent hyperinsulinemia and fetal macrosomia by reducing maternal glucose levels. ${ }^{6}$ This is initially attempted by dietary and exercise counseling, but women often require additional treatment, which has traditionally been insulin. The percentage of GDM patients needing pharmacological treatment varies from $20-60 \%$ in various studies. ${ }^{7}$ However, the disadvantages of insulin in 
pregnant women, includes the risk of hypoglycemia, appreciable weight gain and repeated insulin injections.

Theoretically, metformin is an alternative to insulin in the treatment of hyperglycemia during pregnancy. It decreases hepatic gluconeogenesis and improves peripheral glucose uptake. ${ }^{8}$ It does not induce hypoglycemia and it is not associated with appreciable weight gain. Although it crosses the placenta, there is no evidence of adverse fetal effects ${ }^{9,10}$ or increased risk of major malformations when metformin is used in pregnant women. $^{11}$

In general, the number of studies reporting the use of metformin in pregnancy with type 2 DM or GDM is few. One retrospective study reported increased rates of preeclampsia and perinatal loss in a cohort of women with GDM or type 2 DM treated with metformin compared with a reference group treated with insulin, ${ }^{12}$ but the groups were not well matched for age or Body Mass Index (BMI). Over the past 5 years several studies in Australasia, have been using metformin in selected women during pregnancy. An audit of metformin use in Auckland has not shown any increase in perinatal mortality or preeclampsia in treated women. ${ }^{13} \mathrm{~A}$ prospective Randomized Controlled Trial (RCT) comparing metformin with insulin in women with GDM [Metformin in Gestational Diabetes (MiG) trial] has now been completed in New Zealand and Australia. ${ }^{15}$ This trial recruited 750 women over a period of 2 years. In a small pilot study, in which 30 women who were allocated in random to metformin or insulin therapy showed no adverse maternal or perinatal outcome.

In this prospective study we have tried to assess the efficacy of metformin in the management of GDM and tried to compare metformin with insulin in management of GDM.

\section{METHODS}

It is a prospective comparative study performed in a tertiary centre. The study protocol was approved by institutional ethical committee. 100 women diagnosed with gestational diabetes mellitus according to DIPSI criteria at booking and/or between 24-28 weeks of gestation. DIPSI criteria is 2 hours post prandial $>140$ $\mathrm{mg} / \mathrm{dl}$ (following a 75 gram glucose load) at booking and/or at 24-28 weeks of pregnancy. Pre-gestational diabetes mellitus, multiple pregnancy, congenital anomaly and mother with liver or kidney diseases are excluded from the study.

Once they were diagnosed by the above DIPSI criteria; these women were divided alternately into two groups, even number patients in one group and odd number patient in another group containing 50 patients in each group. Women with gestational diabetes when subjected to pharmacological treatment are given either insulin or metformin, after taking informed consent.
In group 1: The patients are given diabetic diet and started on tablet metformin $500 \mathrm{mg}$ once daily. If not controlled in 1 week, dosage is increased to $500 \mathrm{mg}$ twice daily after food. Maximum dosage of $1700 \mathrm{mg} /$ day $(850$ $\mathrm{mg}$ twice daily) is given. During this period capillary blood glucose by self-testing is done. Good glycemic control is considered when fasting sugar was $<90 \mathrm{mg} / \mathrm{dl}$ and 2 hours post prandial $<120 \mathrm{mg} / \mathrm{dl}$. If there is poor control even after maximum metformin dosage, these patients are switched over to insulin treatment.

In group 2: The patients are given diabetic diet and started on human insulin in $2 / 3^{\text {rd }}$ and $1 / 3^{\text {rd }}$ regimen. The doses of insulin is titrated accordingly, to achieve optimal control described above.

Optimum glycemic control between the two groups is studied along with maternal satisfaction about treatment modality.

All categorical variables have been compared across the two groups using Chi square test for independence of attributes, while all continuous variables has been compared across the two groups using Student's t test (Unpaired t test). Level of Significance is taken as 5\% i.e. if $\mathrm{P}$ value $<0.005$ there is significant difference across the 2 groups else there is no significant difference across the two groups.

\section{RESULTS}

Our study to compare the efficacy of metformin vs. human insulin in GDM patients, showed no significant difference in the use of metformin or insulin $(P=0.15)$. $84 \%$ of insulin group had good glycemic control whereas in metformin group, $72 \%$, achieved euglycemic state. Of the 50 women assigned to metformin, $84 \%$ continued to receive metformin until delivery and $16 \%$ received supplemental insulin. Age distribution, gravida, gestational age at the time of diagnosis of GDM between metformin and insulin group were comparable (Table1). Thus the primary objective of the study showed that there is no difference while using metformin or insulin in GDM patients in achieving glycaemic control (Table 2). In the Moore et al. study, ${ }^{14}$ no patient failed metformin and required insulin. In the 2008, Rowan JA et al. study ${ }^{15} 92.6 \%$ continued to receive metformin and $46.3 \%$ received supplemental insulin.

Table 1: Demographic profile between metformin and insulin groups.

\begin{tabular}{|llll|}
\hline & $\begin{array}{l}\text { Metformin } \\
\text { group }\end{array}$ & Insulin group & $\begin{array}{l}\text { P } \\
\text { value }\end{array}$ \\
\hline Age distribution & $30 \pm 4.23$ & $28.6 \pm 3.37$ & 0.477 \\
\hline Gravida & $2.52 \pm 1.83$ & $2.16 \pm 1.26$ & 0.249 \\
\hline $\begin{array}{l}\text { Mean gestational } \\
\text { age of diagnosis } \\
\text { of GDM }\end{array}$ & $28.12 \pm 4.212$ & $25.92 \pm 4.964$ & 0.483 \\
\hline
\end{tabular}


Table 2: Control of blood sugar between metformin and insulin groups.

\begin{tabular}{|c|c|c|c|c|}
\hline \multirow[b]{2}{*}{$\begin{array}{l}\text { Maintain } \\
\text { ed target } \\
\text { BS levels }\end{array}$} & Group & & \multirow[b]{2}{*}{$\begin{array}{l}\mathbf{P} \\
\text { value }\end{array}$} & \multirow[b]{2}{*}{ Significance } \\
\hline & $\begin{array}{l}\text { Metformin } \\
\text { group } \\
(\mathbf{N}=50)\end{array}$ & $\begin{array}{l}\text { Insulin } \\
\text { group } \\
(\mathbf{N}=50)\end{array}$ & & \\
\hline $\begin{array}{l}\text { Good } \\
\text { control }\end{array}$ & $36(72 \%)$ & $42(84 \%)$ & \multirow{2}{*}{0.15} & \multirow{2}{*}{$\begin{array}{l}\text { Not } \\
\text { Significant }\end{array}$} \\
\hline $\begin{array}{l}\text { Poor } \\
\text { control }\end{array}$ & $14(28 \%)$ & $8(16 \%)$ & & \\
\hline
\end{tabular}

In our study, during antenatal period it was seen, maximum patients $(56 \%)$ diagnosed with GDM were around 26-30 weeks period of gestation. 4 patients developed mild preeclampsia in the metformin group; whereas there was no patient developing preeclampsia in insulin group. $12 \%$ in metformin group developed polyhydramnios whereas only $8 \%$ in insulin group showed polyhydramnios on growth scan. But we have not found any mention of polyhydramnios in the literatures that we have reviewed. $20 \%$ in metformin group developed Abdominal Circumference (AC) $>90^{\text {th }}$ percentile and $24 \%$ metformin group developed $\mathrm{AC}>75^{\text {th }}$ percentile (Table 3).

Table 3: Fetal growth between metformin and insulin groups.

\begin{tabular}{|c|c|c|c|c|}
\hline & \multicolumn{2}{|l|}{ Group } & \multirow[b]{2}{*}{$\begin{array}{l}\mathbf{P} \\
\text { value }\end{array}$} & \multirow[b]{2}{*}{$\begin{array}{l}\text { Significan } \\
\text {-ce }\end{array}$} \\
\hline & $\begin{array}{l}\text { Metformin } \\
\text { group } \\
(\mathbf{N}=\mathbf{5 0})\end{array}$ & $\begin{array}{l}\text { Insulin } \\
\text { group } \\
(\mathbf{N}=\mathbf{5 0})\end{array}$ & & \\
\hline $\begin{array}{l}\text { Polyhydr- } \\
\text { amnios }\end{array}$ & $6(12 \%)$ & $4(8 \%)$ & 0.51 & \multirow{4}{*}{$\begin{array}{l}\text { Not } \\
\text { Significan }\end{array}$} \\
\hline $\begin{array}{l}\mathrm{AC}>90^{\text {th }} \\
\text { percentile }\end{array}$ & $10(20 \%)$ & $12(24 \%)$ & 0.63 & \\
\hline $\begin{array}{l}\mathrm{AC}>75^{\text {th }} \\
\text { percentile }\end{array}$ & $12(24 \%)$ & $20(40 \%)$ & 0.09 & \\
\hline $\begin{array}{l}\text { Large for } \\
\text { gestational } \\
\text { age at birth }\end{array}$ & $6(12 \%)$ & $2(4 \%)$ & 0.14 & \\
\hline
\end{tabular}

During the intranatal period it was seen that equal number of cases from each group (14 cases in each group) underwent emergency caesarean section. $30 \%$ of metformin group underwent spontaneous vaginal delivery whereas only $20 \%$ in the insulin group. Elective caesarean section done in 15 cases of metformin group and 22 cases in the insulin group (Table 4). In the Moore et al. study, ${ }^{14}$ the difference in the rate of caesarean delivery was not statistically significant between the two groups $(\mathrm{P}=0.0102)$. Thus their study is comparable with our study results. In our study, average age of delivery in the metformin group was very similar to insulin group $(37.52 \pm 0.91$ weeks vs. $37.60 \pm 0.81$ weeks; $\mathrm{P}$ value 0.643 ) and mean weight of gestation in the metformin group was also similar to insulin group (2887.24 \pm 400 gms vs. $2926 \pm 511$ gms; $\mathrm{P}$ value 0.670 ).

Table 4: Mode of delivery between metformin and insulin groups.

\begin{tabular}{|lllll|}
\hline $\begin{array}{l}\text { Mode of } \\
\text { delivery }\end{array}$ & $\begin{array}{l}\text { Group } \\
\text { Metformin } \\
\text { group } \\
\mathbf{( N = 5 0 )}\end{array}$ & $\begin{array}{l}\text { Insulin } \\
\text { group } \\
\mathbf{( N = 5 0 )}\end{array}$ & $\begin{array}{l}\mathbf{P} \\
\text { value }\end{array}$ & $\begin{array}{l}\text { Significan } \\
\text {-ce }\end{array}$ \\
\cline { 1 - 2 } $\begin{array}{l}\text { Elective } \\
\text { LSCS }\end{array}$ & $15(30 \%)$ & $22(44 \%)$ & & \\
\cline { 1 - 2 } $\begin{array}{l}\text { Emergency } \\
\text { LSCS }\end{array}$ & $14(28 \%)$ & $24(28 \%)$ & & Not \\
\cline { 1 - 2 } $\begin{array}{l}\text { Spontaneo- } \\
\text { us vaginal } \\
\text { delivery }\end{array}$ & $15(30 \%)$ & $10(20 \%)$ & & Significant \\
\cline { 1 - 2 } $\begin{array}{l}\text { Assisted } \\
\text { vaginal } \\
\text { delivery }\end{array}$ & $6(12 \%)$ & $4(8 \%)$ & & \\
\hline
\end{tabular}

During postnatal period, it was seen that 2 babies expired in the neonatal period in the insulin group only. Both the babies were low birth weight and were admitted in NICU and developed sepsis. No such mishap occurred in the group which received metformin. Hypoglycemia developed in 4 babies of insulin group and 2 cases in metformin group. Even the number of neonatal jaundice was fewer $(36 \%)$ in metformin group.

Table 5: Neonatal morbidity between metformin and insulin groups.

\begin{tabular}{|c|c|c|c|c|}
\hline & \multicolumn{2}{|l|}{ Group } & \multirow[b]{2}{*}{ P value } & \multirow[b]{2}{*}{ Significance } \\
\hline & $\begin{array}{l}\text { Metformin } \\
\text { group }(\mathrm{N}=50)\end{array}$ & $\begin{array}{l}\text { Insulin group } \\
(\mathbf{N = 5 0 )}\end{array}$ & & \\
\hline Neonatal jaundice & $16(32 \%)$ & $12(24 \%)$ & 0.33 & \multirow{9}{*}{ Not significant } \\
\hline Hypoglycemia & $2(4 \%)$ & $4(8 \%)$ & 0.40 & \\
\hline Phototherapy & $16(32 \%)$ & $12(24 \%)$ & 0.37 & \\
\hline NICU admission & $12(24 \%)$ & $12(24 \%)$ & 1.00 & \\
\hline Shoulder dystocia & 0 & 0 & & \\
\hline 1 minute APGAR $($ mean \pm SD) & $7.2 \pm 1.03$ & $6.76 \pm 1.52$ & 0.093 & \\
\hline 5 minute APGAR $($ mean \pm SD) & $7.8 \pm 1.11$ & $7.44 \pm 1.71$ & 0.216 & \\
\hline 10 minute APGAR $($ mean \pm SD) & $7.96 \pm 1.08$ & $7.88 \pm 1.86$ & 0.793 & \\
\hline NICU stay (days) & $2.67 \pm 1.77$ & $3.50 \pm 2.61$ & 0.370 & \\
\hline
\end{tabular}


There were no cases of RDS in either group as most of the babies delivered at term.

In 2008, MiG trial ${ }^{15}$ also showed no adverse effects on neonate outcome when metformin was used.

In our study, no case of shoulder dystocia was encountered even though 2 LGA babies delivered in the insulin group, and 6 cases in metformin group. The average birth weight were similar in both groups $(\mathrm{P}=$ $0.670) ; 2887.4$ grams in metformin group and 2926.4 grams in insulin group (Table 5).

No case of congenital anomalous baby in either group was detected. The neonatal outcome was similar in both groups $(\mathrm{P}=0.33)$. APGAR score at $5 \mathrm{~min}$ and neonatal jaundice were similar. The mean NICU stay was 2.67 days for metformin group and 3.50 days in insulin group (Table 5).

More women in the metformin group than in the insulin group stated that they would choose to receive their assigned treatment again ( $76 \%$ vs. $18 \%)$.

$5 \%$ were not sure of the type of treatment they want in their next pregnancy.

$80 \%$ of patients felt that that the repeated injection was the most difficult part of the treatment while $8 \%$ felt diet control was the most difficult.

$64 \%$ of the entire study group felt taking oral medications was the easiest part of the study.

\section{DISCUSSION}

In light of the study results, we conclude that in women with gestational diabetes mellitus, metformin (alone or with supplemental insulin) is not associated with increased perinatal complications as compared with insulin.

The women preferred metformin to insulin treatment. These data suggests that metformin is effective in controlling GDM and is not associated with a higher risk of maternal or neonatal complications compared with insulin.

However, further sufficiently powered and randomized clinical studies are still needed, including long-term follow-up of children, in order to determine the role of metformin as an alternative treatment to insulin in GDM patients.

The following conclusions can be drawn from this study:

1. Metformin can be used in the management of gestational diabetes mellitus.
2. No teratogenicity has been proved in the treatment of GDM using metformin. There should be increased awareness regarding the safety of the drug.

3. More extensive studies to be carried out in this field with long term follow up to see any adverse effect of metformin.

4. In GDM, glycemic control can be done with a combination of MNT (medical nutrition therapy), exercise and using the oral drug metformin.

Funding: No funding sources

Conflict of interest: None declared

Ethical approval: The study was approved by the institutional ethics committee

\section{REFERENCES}

1. Glueck C, Goldenberg N, Streicher P, Wang P. Metformin and gestational diabetes mellitus. Curr Diabet Rep. 2003;3:303-12.

2. Jovanovic L, Pettitt D. Gestational diabetes mellitus. J Am Med Assoc. 2001;286:2516-8.

3. Ben-Haroush A, Yogev Y, Hod M. Epidemiology of gestational diabetes mellitus and its association with type 2 diabetes. Diabet Med. 2004;21:103-13.

4. Kim C, Newton K, Knopp R. Gestational diabetes and the incidence of type 2 diabetes. Diabet Care. 2002;25:1862-8.

5. Crowther C, Hiller J, Moss J, McPhee A, Jeffries W, Robinson J. Effect of treatment of gestational diabetes mellitus on pregnancy outcomes. $\mathrm{N}$ Eng $\mathrm{J}$ Med. 2005;352:2477-86.

6. Langer O. Is normoglycemia the correct threshold to prevent complications in the pregnant diabetic patient? Diabet Rev. 1996;4:2-10.

7. Langer O. From educated guess to accepted practice: the use of oral anti-diabetic agents in pregnancy. Clin Obstet Gynecol. 2007;4:959-71.

8. Kirpichinikov D, McFarlane S, Sowers J. Metformin: an update. Ann Intern Med. 2002;137:25-33.

9. Nanovskaya T, Nekhayeva I, Partikeeva S, Hankins G, Ahmed M. Transfer of metformin across the dually perfused human placental lobule. Am J Obstet Gynecol. 2006;195:1081-5.

10. Kovo M, Haroutiunian S, Feldman N, Hoffman A, Glezerman M. Determination of metformin transfer across the placenta cotyledons model. Euro J Obstet Gynecol Reprod Biol 2008;136:29-33.

11. Gilbert C, Valois M, Koren G. Pregnancy outcome after first-trimester exposure to metformin: a metaanalysis. Fertil Steril. 2006;86:658-63.

12. Hellmuth E, Damm P, Molsted-Pedersen L. Oral hypoglycemic agents in 118 diabetic pregnancies. Diabet Med. 2000;17(7):507-11.

13. Jacubowicz D, Iuorno M, Jacubowicz S, Roberts K, Nestler J. Effects of metformin on early pregnancy loss in the polycystic ovary syndrome. J Clin Endocrinol Metab. 2002;87:524-9. 
14. Moore L, Briery C, Clokey D, Martin R, Willford N, Bofill.J, Morrison J. Metformin and insulin in the management of gestational diabetes mellitus. J Reprod Med. 2007;52:1011-5.

15. Rowan J, Hague W, Gao W, Battin M, Moore M. $\mathrm{MiG}$ trial investigators: metformin versus insulin for the treatment of gestational diabetes. N Eng J Med. 2008;358:2003-15.

DOI: $10.5455 / 2320-1770 . i j r \operatorname{cog} 20140614$

Cite this article as: Munshi S, Khandaker S.

Evaluation of metformin versus insulin in the management of gestational diabetes mellitus: a prospective comparative study. Int J Reprod Contracept Obstet Gynecol 2014;3:357-61. 